\title{
Effectiveness of recombinant hepatitis $B$ vaccine with/without the passive hepatitis $B$ immunoglobulin vaccine in babies whose mothers are hepatitis $B$ surface antigen positive in a private missionary hospital
}

\author{
Olusanya Abiodun ${ }^{1 *}$, Omobolaji Onibonoje ${ }^{2}$, Oluwadara Ola $^{2}$, Sophie Ishola ${ }^{2}$
}

\begin{abstract}
${ }^{1}$ Department of Obstetrics and Gynaecology, ${ }^{2}$ Department of Family Medicine, Sacred Heart Hospital, Lantoro, Ogun State, Nigeria
\end{abstract}

Received: 11 March 2021

Revised: 13 April 2021

Accepted: 26 April 2021

\section{*Correspondence:}

Dr. Olusanya Abiodun,

E-mail: biodunolusanya@yahoo.com

Copyright: $(\mathcal{C}$ the author(s), publisher and licensee Medip Academy. This is an open-access article distributed under the terms of the Creative Commons Attribution Non-Commercial License, which permits unrestricted non-commercial use, distribution, and reproduction in any medium, provided the original work is properly cited.

\section{ABSTRACT}

Background: Hepatitis B infection is a potentially life-threatening liver infection. The burden is more in the less developed countries. Vaccination is the most cost-effective way to control hepatitis B virus (HBV) infection and its chronic complications globally. Active-passive immunoprophylaxis using hepatitis B immunoglobulin combined with recombinant hepatitis B vaccine is recommended for infants of women with chronic HBV infection. This study aimed to determine the effectiveness of the hepatitis B recombinant vaccine alone or combined with hepatitis B immunoglobulin.

Methods: The study was a prospective longitudinal study. Patients were selected using a convenient sampling technique. The study spanned between 1 January 2017 and 31 December 2018. Data analysis was with SPSS version 21.

Results: The unit recorded 1690 deliveries during the recruitment period, 70 eligible patients were recruited thus giving an incidence of $4.1 \%$. $74.3 \%$ of the recruited patients were $\mathrm{HBeAg}$ negative while $25.7 \%$ were $\mathrm{HBeAg}$ positive. $52.9 \%$ of the babies had only recombinant HB recombinant vaccine while $47.1 \%$ had combined hepatitis B immunoglobulin and the recombinant vaccine at birth. The $\mathrm{HBeAg}$ status of mothers played a significant factor in the HBsAg positivity of babies two months after the completion of immunoprophylaxis against HBV.

Conclusions: Giving recombinant HBV vaccine in combination with the HBV immunoglobulin is the standard practice, this may not always be so based on the findings from this study. However, the population studied is too small to make a categorical statement thus a larger population needs to be studied.

Keywords: Hepatitis B virus, Hepatitis B recombinant vaccine, Hepatitis B immunoglobulin

\section{INTRODUCTION}

Hepatitis B infection is a potentially life-threatening liver infection caused by the HBV. ${ }^{1}$ The virus is one of the most prevalent blood-borne viruses worldwide with the affectation of the liver leading to a chronic liver disease state that includes liver cirrhosis and hepatocellular carcinoma. ${ }^{2,3}$ The global burden of the HBV infection is enormous with an annual mortality of more than 686,000 as a result of the complications that include liver cirrhosis and hepatocellular carcinoma; 800,000-1.4 million people in the United States of America and more than 257 million people are living with chronic HBV infection worldwide, $88 \%$ of whom reside in sub-Saharan Africa 
(SSA) ${ }^{1,4-6}$ HBV has constituted a major public health problem worldwide with its sequelae, the burden of the disease is especially high in less developed countries. ${ }^{2,4}$

The acquisition of the HBV is a key determinant of chronicity. When the infection occurs in adulthood it usually leads to an acute resolved infection and then immunity is developed, however in contrast when the infection occurs during the perinatal or neonatal period it less likely leads to a chronic infection state with its attending longstanding risks. ${ }^{2,5,7}$ About $90 \%$ of exposed infants without HBV vaccine will develop chronic HBV infection compared to $5-10 \%$ of exposed immunecompetent adults. ${ }^{5}$ Among individuals with chronic HBV infection, regardless of the timing of infection, $20 \%$ will eventually die from complications of $\mathrm{HBV}$ infection including cirrhosis and hepatocellular carcinoma. ${ }^{4}$

The global prevalence of HBV carriers varies widely from high (10-20\%) in south-east Asia and China to intermediate $2.7 \%$ in the Mediterranean region, Japan, central Asia and the Middle East and low $(<2 \%)$ in the United States of America, Canada, western Europe and Australia. ${ }^{8}$ The number of people who are positive for HBV in Nigeria is not known, however, several studies have been carried out in various population groups in the country. ${ }^{9-12}$ The prevalence of hepatitis B surface antigen among normal Nigerian population was reported from a minimum of $2 \%$ to a maximum of $14.3 \% .{ }^{10}$ However, the study carried out by Onakewhor et al in Benin Nigeria in 2013 among antenatal patients found a prevalence of $4.3 \%{ }^{9} \mathrm{HBV}$ can be classified according to its prevalence as low $(<2 \%)$, moderate $(2-7 \%)$ and high $(7 \%) .{ }^{13}$

One of the most important routes of HBV transmission is from asymptomatic carrier mothers to their infants. ${ }^{9}$ Such perinatal transmission accounts for between $35-50 \%$ of HBV carriers. ${ }^{5,14}$ This perinatal transmission constitutes the major source of perpetuating the reservoir of chronically infected individuals globally.

WHO has set a goal of disease elimination by 2030 , reaching this ambitious goal will require a significant scale-up of prevention and treatment efforts in SSA, with a focus on efforts to prevent the transmission of $\mathrm{HBV}$ during pregnancy and the peripartum period. ${ }^{15-17}$

Vaccination is the most cost-effective way to control HBV infection and its chronic complications on a global scale. ${ }^{18}$ To reverse the trend in the prevalence of hepatitis B surface antigen (HBsAg) in the SSA screening for HBsAg during the antenatal period provides the perfect opportunity, this is because pregnant women present to the hospital during the period and avail themselves to be screened for the infection as part of the routine antenatal check-up. ${ }^{12}$ The mainstay of preventing HBV acquisition at birth comprises at least 3 doses of hepatitis B vaccine, including a birth dose administered on time within $24 \mathrm{hrs}$ of birth, this timely administration will reduce the risk of chronic HBV infection to $10-15 \%{ }^{19,20}$
Mother-to-child transmission occurs in 5\%-15\% of infants in the absence of specific prophylaxis. ${ }^{21,22}$ The rate of infection in neonates is associated with the maternal viral load and $\mathrm{HBeAg}$ positivity. ${ }^{22-23}$ In mothers who are seropositive for both $\mathrm{HBsAg}$ and $\mathrm{HBeAg}$, vertical transmission can occur at an approximate rate of $90 \% .^{21-23}$

Active-passive immunoprophylaxis through the use of hepatitis B immunoglobulin combined with the recombinant hepatitis $\mathrm{B}$ vaccine is recommended among infants born to women with chronic HBV infection, however studies have equally shown that giving only the recombinant hepatitis $B$ vaccines may also be effective. ${ }^{19,24,25}$ Evidence regarding the effectiveness of the administration of $\mathrm{HBIG}$ to infants born to $\mathrm{HBeAg}$ positive/HBeAg negative mothers are controversial. ${ }^{26-28}$

Despite the relatively excellent efficacy of high titre HBIG and HBV vaccination as post-exposure prophylaxis (PEP) in newborns, in $3 \%$ to $9 \%$ of children born to mothers with positive HBV serum markers, this strategy fails to block MTCT of the virus. ${ }^{29,30}$ Administration of a 3 or 4 dose series of recombinant hepatitis B vaccine starting within 12 hours after delivery without HBIG has a protective efficacy of $70-95 \%$ in mothers with both HBsAg and HBeAg. ${ }^{31,32}$ Studies have equally shown that where HBIG is unavailable, vaccination alone can prevent vertical transmission in 60$90 \%$ of cases. ${ }^{24,33}$ Meta-analysis carried out by Macharia et al in 2014 revealed that the combination of the HBV vaccine with HBIG was not significantly associated with lower seroprotection rates compared with $\mathrm{HBV}$ vaccine alone. ${ }^{24}$ This will be pertinent in our environment where the cost of living is very high and access to health services is almost beyond the rich of the common man coupled with the exorbitant cost of a vial of the HBIG that is about $\$ 60,000.00$ precludes its use in most situations.

\section{Hypothesis}

Hepatitis B vaccine alone as well as combined active and passive immune prophylaxis is effective against HBV.

\section{Aim}

This study aimed to determine the effectiveness of recombinant hepatitis $\mathrm{B}$ vaccine alone or combined with hepatitis B immunoglobulin.

\section{METHODS}

This was a prospective longitudinal study, recruitment and follow-up of participants were between 1 January 2018 and 31 December 2019. The recruitment of patients was done in the first year using a convenience sampling technique. The study was carried out to assess the effectiveness of recombinant HBV vaccine alone or in combination with HBV immunoglobulin in babies whose 
mothers were HBV positive. Hepatitis positive patients irrespective of their $\mathrm{HBeAg}$ status were recruited for this study.

Patients that declined to participate, those with multiple gestations and those with jaundice irrespective of the aetiology were excluded from the study

\section{Study setting and subjects}

The antenatal clinic, the antennal ward and the labour ward of the obstetrics and gynaecology unit of Sacred heart hospital, Lantoro, Abeokuta in Ogun state. The subjects were the pregnant women who were HBsAg positive irrespective of the $\mathrm{HBeAg}$ status seen at these points of care in the unit.

The hospital is a 300 bedded hospital with the obstetrics and gynaecology unit having 88 beds in various parts of the department. The hospital is the first hospital in Nigeria with clienteles in the whole of the south-west of the country. As part of the routine antenatal protocol of the hospital, all pregnant women are counselled and screened for HBV at booking, those patients that tested positive for HBsAg were also screened for $\mathrm{HBeAg}$ to determine their HBeAg positivity; if they met the inclusion criteria were counselled and recruited for the study after informed written consent was obtained. At delivery about 3-5 $\mathrm{ml}$ of the cord blood sample was collected in a universal bottle, centrifuged and tested for HBsAg. Amongst the clients recruited for the study those that could afford to buy the HBIG were encouraged to make it available at delivery and their babies were given the immunoglobulin alongside the recombinant hepatitis $B$ vaccine while the babies of those that could not afford the HBIG were given the recombinant hepatitis B vaccine alone and continued on the hepatitis vaccine protocol. 2 months after the completion of the immunization protocol $5 \mathrm{ml}$ of blood from the antecubital fossa of all the babies who had either HBV vaccine with HBIG or the vaccine alone was collected, centrifuged and tested for HBsAg to assess the effectiveness of the immunization.

\section{Determination of sample size}

The prevalence of $4.3 \%$ from the study carried out among pregnant women with HBsAg in Benin Nigeria by Onakewhor et al was used to determine the sample size for this study. Data were analysed with SPSS version 21.

The minimum sample size was calculated using this formula,

$\mathrm{n}=\frac{Z^{2} p q}{d^{2}}$

where, $\mathrm{n}=$ minimum sample size,

that had scarification mark was $37.1 \%$ and $24.3 \%$ of the respondents had one form of female circumcision or the
$\mathrm{Z}=$ standard normal deviation $=1.96$,

$\mathrm{p}=$ the proportion estimated to have a characteristic which is $4.3 \%(0.043)$,

$\mathrm{q}=1.0-\mathrm{p}=1-0.043=0.957$,

$\mathrm{d}=$ degree of accuracy desired which is $5 \%(0.05)$,

$\mathrm{n}=\frac{1.96^{2} \times 0.043 \times 0.957}{0.05^{2}}$,

$\mathrm{n}=63$.

Attrition rate of $10 \%=6.3$,

Total sample size is $63+6.3=69.3$,

The total sample size was 70 .

\section{Outcome measures}

The outcome measures were incidence of HBsAg positivity in babies of $\mathrm{HBsAg}$ positive mothers after $\mathrm{HBV}$ vaccine, effect of maternal $\mathrm{HBeAg}$ status on $\mathrm{HB}$ status of babies after vaccination, effectiveness of HBV vaccine alone, effectiveness of vaccine combined with the HBIG.

\section{RESULTS}

During the period of study recruitment, the obstetrics and gynaecology department recorded a total of 1690 deliveries out of which 70 consecutive pregnant patients with $\mathrm{HBsAg}$ irrespective of their $\mathrm{HBeAg}$ status that met the inclusion criteria were recruited thus giving an incidence of $4.14 \%$.

The sociodemographic characteristics of the respondents revealed that $12.9 \%$ of the respondents were between the ages of 36 and 40 years while $2.9 \%$ of them were either 20 years or less. The booked patients made up $92.9 \%$ while $7.1 \%$ did not book for antenatal care in the facility, $44.3 \%$ were primigravidae while $52.9 \%$ were either primipara or multipara and only $2.9 \%$ were grand multipara. The respondents with tertiary education were $48.6 \%$, while only $9 \%$ of the respondents had no form of formal education (Table 1).

The possible risk-predisposing factors for HBV identified in the patients recruited for the study. $72.9 \%$ of the partners were $\mathrm{HBsAg}$ negative while $27.1 \%$ of the partners HBsAg were positive. Most of the respondents were in their first marriage with a value of $97.1 \%, 75.7 \%$ were in a monogamous type of marriage and $24.3 \%$ were in a polygamous marriage. The number of respondents

other. Only $4.3 \%$ of the patients had been transfused with blood in the past before pregnancy (Table 2). 
The HBeAg status of the respondents was that $74.3 \%$ of the patients were $\mathrm{HBeAg}$ negative while $25.7 \%$ were HBeAg positive (Figure 1).

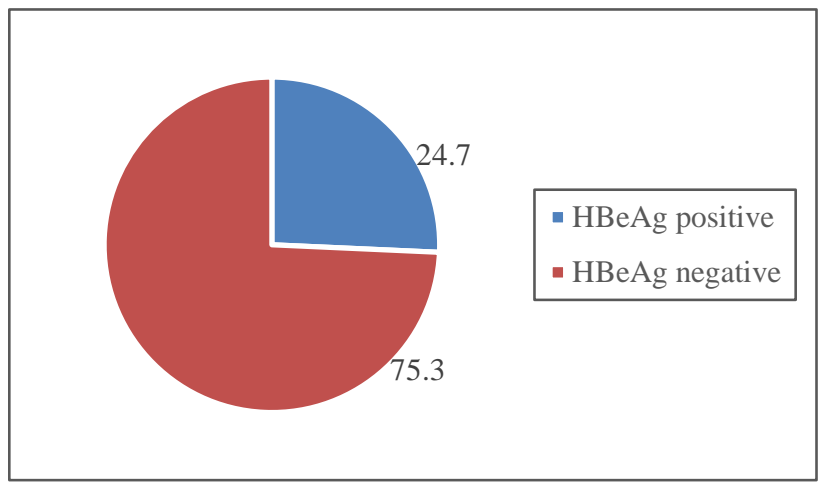

Figure 1: HBeAg status of the respondents.

The cord blood HBsAg status of the babies of the respondents recruited before the administration of $\mathrm{HBV}$ immunoprophylaxis. Among the cord blood samples tested for $\mathrm{HBsAg}, 12.9 \%$ were positive for $\mathrm{HBsAg}$ while $87.1 \%$ were negative (Figure 2 ).

Table 1: Sociodemographic characteristics of respondents.

\begin{tabular}{|lll|}
\hline Sociodemographic characteristics & $\mathbf{N}=\mathbf{7 0}$ & Percentage (\%) \\
\hline Age (in years) & 2 & 2.9 \\
\hline$\leq 20$ & 9 & 12.9 \\
\hline $21-25$ & 30 & 42.9 \\
\hline $26-30$ & 20 & 28.6 \\
\hline $31-35$ & 9 & 12.9 \\
\hline $36-40$ & & 92.9 \\
\hline Booking status & 65 & 7.1 \\
\hline Booked & 5 & 44.3 \\
\hline Unbooked & & 52.9 \\
\hline Parity & 31 & 2.9 \\
\hline 0 & 37 & \\
\hline $1-4$ & 2 & 2.9 \\
\hline$\geq 5$ & & 20 \\
\hline Educational status & 2 & 28.6 \\
\hline None & 14 & 48.6 \\
\hline Primary & 20 & \\
\hline Secondary & 34 & \\
\hline Tertiary & & \\
\hline
\end{tabular}

Table 2: Risk factors $\mathrm{HBV}$ infection identified in the respondents.

\begin{tabular}{|lll|}
\hline Risk factors & $\mathbf{N}=\mathbf{7 0}$ & Percentage (\%) \\
\hline Partner's status & & 27.1 \\
\hline HBsAg positive & 19 & 72.9 \\
\hline HBsAg negative & 51 & 2.9 \\
\hline History divorce & & 97.1 \\
\hline Yes & 2 & 75.7 \\
\hline No & 68 & 24.3 \\
\hline Type of marriage & & \\
\hline Monogamous & 53 & \\
\hline Polygamous & 17 & \\
\hline
\end{tabular}

Continued. 


\begin{tabular}{|lll|}
\hline Risk factors & $\mathbf{N = 7 0}$ & Percentage (\%) \\
\hline Scarification mark & & 37.1 \\
\hline Yes & 26 & 62.9 \\
\hline No & 44 & \\
\hline Female circumcision & & 24.3 \\
\hline Yes & 17 & 75.7 \\
\hline No & 53 & \\
\hline Past transfusion & & 4.3 \\
\hline Yes & 3 & 95.7 \\
\hline No & 67 & \\
\hline
\end{tabular}

Table 3: Immunoprophylaxis type received by babies at delivery.

\begin{tabular}{|lll|}
\hline Type of immunoprophylaxis & $\mathbf{N}=\mathbf{7 0}$ & Percentage (\%) \\
\hline HBV recombinant vaccine only & 37 & 52.9 \\
\hline HBV vaccine+HBV immunoglobulin & 33 & 47.1 \\
\hline
\end{tabular}

Table 4: Type of immunoprophylaxis type at birth and HBsAg status of babies two months after vaccination.

\begin{tabular}{|llll|}
\hline Vaccination type & \multicolumn{2}{l}{ HBsAg status babies after vaccination } & $\mathbf{X}^{2}$ \\
\cline { 2 - 4 } & Negative & Positive & 0.239 \\
\hline HBV vaccine only & 31 & 6 & \\
\hline HBV vaccine + HBV immunoglobulin & 29 & 4 & \\
\hline Total & 60 & 10 & \\
\hline
\end{tabular}

Table 5: Effect of maternal HBeAg status on HBsAg positivity babies two months after vaccination.

\begin{tabular}{|llll|}
\hline HBeAg status of mothers & \multicolumn{2}{l|}{ HBsAg of babies after vaccination } & $\mathbf{X}^{2}$ \\
\hline Negative & Negative & Positive & \multirow{2}{*}{0.001} \\
\hline Positive & 49 & 3 & 7 \\
\hline
\end{tabular}

The HBsAg status of all the babies whose mothers were recruited for the study two months after the completion of the HBV immunoprophylaxis according to the national immunization protocol. Out of the 37 babies that received only HBV recombinant vaccine $6(16.2 \%)$ became positive 2 months after the completion of vaccination while $4(12.1 \%)$ out of the 33 babies that had a combination of HBV recombinant vaccine and HBV immunoglobulin became positive. When the type of immunoprophylaxis had at birth was cross-tabulated with HBsAg at two months after completion of immunization against HBV there was no statistically significant relationship (Table 4).

The cross-tabulation of maternal $\mathrm{HBeAg}$ status and HBsAg status of babies two months after HBV immunoprophylaxis. There was a statistically significant relationship with a p value of 0.001 and RR of 10.394 (95\% CI 2.314 to 46.689 ) (Table 5).

\section{DISCUSSION}

Hepatitis B virus infection is a potentially life-threatening infection whose perpetuation is aided by materno-fetal transmission and the major way to prevent and thereby decreasing its perpetuity is antenatal screening and vaccination of babies born to mothers who are HBsAg positive. This study was carried out to determine the effectiveness of the HBV vaccine with or without HBV immunoglobulin. The study spanned over 24 months. The patients were recruited in the first 12 months while they were followed up in the remaining 12 months. This study was also the first from a private institution. Using a convenient sampling method 70 patients that met the inclusion criteria were recruited for the study. In the first half of the study the unit recorded 1,690 deliveries, this makes the incidence of HBsAg positive in pregnancy to be $4.14 \%$ this is similar to the finding by Onakewhor et al in Benin Nigeria. ${ }^{9}$ In this study partner's hepatitis status did not have any effect on the materno-fetal transmission of the virus as there was no statistically significant relationship between them. It stands to reason since transmission majorly is during passage through the birth canal and rarely through the placenta. ${ }^{3,6}$ In this study maternal $\mathrm{HBeAg}$ positivity had no statistically significant relationship with HBsAg positivity of the cord blood with a p value of 0.028 , however, it is still a risk for hepatitis $B$ virus transmission since it was found in this study that HBsAg positivity was more in the cord blood of the babies whose mothers were HBeAg negative compared to 
the $\mathrm{HBeAg}$ negative mothers. Maternal HBeAg status has a statistically significant relationship with the babies HBsAg status after completion of vaccination with a $p$ value of 0.001 and RR of 10.394, this finding was similar to findings in other climes of the world. ${ }^{7,8,14,24}$ There was no significant relationship between the type of immunoprophylaxis that the babies received at birth and their HBsAg status two months after completing vaccination against $\mathrm{HBV}$ with a $\mathrm{p}$ value of 0.239 , this is similar with studies in other climes., ${ }^{2,7,9,21,31}$ The significance of this finding as it applies to an economicchallenged environment is that giving the hepatitis $\mathrm{B}$ immunoglobulin alongside the recombinant vaccine may not be mandatory since the recombinant HBV alone is equally effective as shown from this study. Be it as it may we cannot conclude because the sample size is small; studies on a wider scale will be necessary before concluding that recombinant hepatitis $\mathrm{B}$ alone will be adequate as immunoprophylaxis against HBV.

The limitations of this included was the fact that it was a hospital-based study and method employed to recruit patients was convenient sampling method so bias was not completely eliminated. The sample size was too small to conclude that recombinant $\mathrm{HBV}$ vaccine would be adequate.

\section{CONCLUSION}

Giving recombinant $\mathrm{HBV}$ vaccine in combination with the HBV immunoglobulin is still the standard practice in the developed world, this may not always be so based on the finding from this study. However, the population studied is too small to make a categorical statement thus a larger population needs to be studied.

\section{ACKNOWLEDGMENTS}

The investigators acknowledged the immense assistance and cooperation of the doctors and nurses in the antenatal clinic, antenatal ward and the labour ward for their assistance and most especially the pregnant women who partook in this study.

Funding: No funding sources Conflict of interest: None declared

Ethical approval: The study was approved by the Institutional Ethics Committee

\section{REFERENCES}

1. WHO. Fact sheet: Hepatitis B, 2016. Available at: ww.who.int/mediacentre/factsheets/fs204/en Accessed on 26 February 2021.

2. Alfonso M, Tancredi F, Romario L, Giuseppone A, Colucci M, Sanguiolo A, et al. Effectiveness of hepatitis $\mathrm{B}$ vaccination in babies born to hepatitis B surface antigen-positive mothers in Italy. JID. 2001; $184: 905-8$.
3. $\mathrm{Hu} \mathrm{Y,} \mathrm{Yu} \mathrm{H.} \mathrm{Prevention} \mathrm{strategies} \mathrm{of} \mathrm{mother-to-child}$ transmission of hepatitis B virus (HBV) infection. Pediatr Invest. 2020;4(2):133-7.

4. Mandel GL, Bennet JE, Dolin R. Mendel, Douglas and Bennett's Principles and Practice of Infectious Diseases. 7th ed. Philadelphia (PA): Churchill Livingstone Elsevier; 2010.

5. Dionne-Odom J, Tita ATN, Silverman NS. Society for maternal-fetal medicine (SMFM) consult series: \#38:hepatitis B in pregnancy screening, treatment, and prevention of vertical transmission. Am J Obst Gyn. 2016;214(1):6-14.

6. Dionne-Odom J, Njei B, Tita ATN. Elimination of vertical transmission of hepatitis $B$ in Africa: a review of available tools and new opportunities. Clin Ther. 2018;40(8):1255-7.

7. Pande C, Sarin SK, Patra S, Kumar A, Mistra S, Srivastva $S$, et al. Hepatitis B vaccination with or without Hepatitis B immunoglobulin at birth to babies born of HBsAg positive mothers prevents overt HBV transmission but may not prevent occult HBV infection in babies: a randomized controlled trial. J Viral Hepat. 2013;20(11):801-10.

8. Yahyapour Y, Karim M, Molaei H, Khoddami E, Mahmoudi M. Active-Passive Immunization Effectiveness Against Hepatitis B Virus in Children Born to HBsAg Positive Mothers in Amol, North of Iran. Oman Med J. 2011;26(6):399-403.

9. Onakewhor JUE, Charurat M, Mathew O, Osagie E, Asemota MO, Omoigherale A. Immunologic pattern of hepatitis B Infection among Exposed and NonExposed Babies in A PMTCT Program in Low Resource Setting: Does Every Exposed Newborn Require 200iu of Hepatitis B Immunoglobulin? J vaccines vaccinat.2013;4(7):1-6.

10. Nwokediuko SC. Chronic hepatitis B: management challenges in resource-poor countries. Hepat Mon. 2011;11(10):786-93.

11. Okonkwo I, Okerentugba $\mathrm{P}$, Innocent-Adiele $\mathrm{H}$. Detection of hepatitis B surface antigen (HBsAg) among children in Ibadan, Southwestern Nigeria. Intern J Infect Dis. 2012;10(1):1-7.

12. Ogunlejo OA, Fawole AA, Adeniran AS, Olawunmi HO, Ogunleye IP. Mother to child transmission of hepatitis B virus in the university of Ilorin teaching hospital, Nigeria. Int $\mathrm{J}$ Res Medi Heal Sci. 2014;4(2):1-6.

13. Madrey WC. Hepatitis B: an important public health issue. J Med Virol. 2000;61(8):362-6.

14. Yao JL. Perinatal transmission of hepatitis B virus infection and vaccination in China. Gut. 1996;38(2):37-8.

15. United Nations. Sustainable Development Goals. 2015. https://www.un.org. Accessed on 26 February 2021.

16. WHO. Fact sheet: Combating Hepatitis B and C to Reach Elimination by 2030. Available at: https://www.who.int. Accessed on 27 February 2021.

17. Spearman CW, Afihene M, Ally R, Apica B, Awuku $\mathrm{Y}$, Cunha L, et al. Hepatitis B in sub-Saharan Africa: 
strategies to achieve the 2030 elimination target. Lancet Gastroenterol Hepatol. 2017;2(12):900-9.

18. Chen SC, Toy M, Yeh JM, Wan J, Resch S. Costeffectiveness of augmenting universal hepatitis B vaccination with immunoglobulin treatment. Paed. 2013;131(4):1135-43.

19. Hou J, Cui F, Ding Y, Dou X, Duan Z, Hau G, et al. Management algorithm for interrupting mother-tochild transmission of hepatitis B Virus. Clin Gastroenterol Hepatol. 2019;17(10):1920-36.

20. WHO. Fact sheet: Hepatitis B Vaccines, 2017. https://www.who.int. Accessed on 27 February 2021.

21. Hashemi-Shahri SM, Khalili SM. Review of the prevention of hepatitis B virus infection transmission from mother to child during pregnancy. Int J Infect. 2015;2(3):26626.

22. Nelson NP, Jamieson DJ, Murphy TV. Prevention of perinatal hepatitis B virus transmission. J Pediat Infect Dis Soc. 2014;3(1):7-12.

23. Geeta MG, Riyaz A. Prevention of mother to child transmission of hepatitis B infection. Ind Pediat. 2013:50(2):189-92.

24. Machaira M, Popaevangelou V, Vouloumanou EK, Tansarli GS, Falagas ME. Hepatitis B vaccine alone or with hepatitis $\mathrm{B}$ immunoglobulin in neonates of $\mathrm{HBsAg}+/ \mathrm{HBeAg}$ - mothers: a systematic review and meta-analysis. J Antimicros Chemother. 2015;70(2):396-404.

25. Lu Y, Liang XF, Wang FZ, Yan L, Li R, Li Y, et al. Hepatitis $B$ vaccine alone may be enough for prevention of hepatitis $\mathrm{B}$ virus transmission in neonates of $\mathrm{HBsAg}(+) / \mathrm{HBeAg}(-)$ mothers. Vaccine. 2017;35(1):40-5.

26. Lee C, Gong Y, Brok J, Boxall EH, Glund C. Effect of hepatitis $\mathrm{B}$ immunization in newborn infants of mothers positive for hepatitis B surface antigen: systematic review and meta-analysis. BMJ. 2006:332(7537):328-36.

27. Yang Y, Liu C, Chen T, Lee M, Chen S, Shih H, et al. Role of hepatitis B Immunoglobulin in infants born to Hepatitis B positive carrier mothers in Taiwan. Pediatr Infect Dis J. 2003;22(7):584-8.

28. Lo KJ, Tsai YT, Lee SD, Wu TC, Wang JY, Chen $\mathrm{GH}$, et al. Immunoprophylaxis of infection with hepatitis B surface antigen-positive carrier mothers. J Infect Dis. 1985;152(4):817-22.

29. Wiseman E, Frazer MA, Holden S, Glass A, Kidson BL, Heron LG, et al. Perinatal transmission of hepatitis B virus an Australian experience. Med J Aust. 2009;190:489-92.

30. Navabakhsh B, Mehrabi N, Estakhri A, Mohamadnejad M, Poustchi H. Hepatitis B Virus infection during pregnancy: transmission and prevention. Middle East J Digest Dis. 2011;3(2):92102.

31. Poovorawan Y, Sanpavat S, Pongpunlert W, Chumdermpadetsuk S, Sentrakul P, Chitinand S, et al. Comparison of a recombinant DNA hepatitis B vaccine alone or in combination with hepatitis $B$ immunoglobulin for the prevention of perinatal acquisition of hepatitis B carriage. Vaccine. 1990:569.

32. Gambarin GM. Hepatitis B in pregnancy. Clin.Liver Dis. 2007;11(4);945-63.

33. Geeta MG, Rivaz A. Prevention of mother to child transmission of hepatitis B infection. Ind Paediatr. 2013;50(2):189-92.

34. Chen Z, Zeng M, Liu D, Wu L, Zhang L. Antenatal administration of hepatitis $\mathrm{B}$ immunoglobulin and hepatitis $\mathrm{B}$ vaccine to prevent mother to child transmission in HBsAg positive pregnant women: A systematic review and meta-analysis. Med. 2020;99(16):19886.

Cite this article as: Abiodun $\mathrm{O}$, Onibonoje $\mathrm{O}$, Ola $\mathrm{O}$, Ishola S. Effectiveness of recombinant hepatitis B vaccine with/without the passive hepatitis $B$ immunoglobulin vaccine in babies whose mothers are hepatitis B surface antigen positive in a private missionary hospital. Int J Reprod Contracept Obstet Gynecol 2021;10:2383-9. 